\title{
RANCANG BANGUN SISTEM STARTER SEPEDA MOTOR MENGGUNAKAN SMARTPHONE BERBASIS MIKROKONTROLLER
}

\author{
Indranata U. Panggalo1*, Rocky Yefrenes Dillak ${ }^{2}$, Floriano J.X.S. Da Silva ${ }^{3}$ \\ ${ }_{1,2,3}$ Politeknik Negeri Kupang \\ JI. Adi Sucipto Penfui Kupang - NTT. P.O.Box. 139 \\ *E-mail: indrapanggalo@gmail.com \\ rocky_dillak@yahoo.com \\ flo_dasilva@gmail.com
}

\begin{abstract}
Abstrak
Meningkatnya penggunaan sepeda motor tidak terlepas dari tingkat kebutuhan, prestise, hobby maupun demografi sebuah daerah atau Negara. Indonesia merupakan salah satu negara berkembang dengan jumlah peduduk yang cukup padat yaitu mencapai 5 terpadat dunia. Dengan jumlah penduduk yang padat maka diikuti pula jumlah pengguna kendaraan bermotor. Saat ini menurut data BPS pertahun 2016, bahwa pengguna kendaraan bermotor 129 jutadan 105,15 juta adalah pengguna sepeda motor. Meningkatnya penggunaan sepeda motor ternyata diikuti pula oleh tingginya pencurian sepeda motor. Sistem keamanan pada sepeda motor, terutama pada bagian sistem kontak dan starter mesin. Sistem pengunci dari pabrikan belum mengalami perubahan berarti dan masih cendderung sama. Hal inilah yang menyebabkan pencuri leluasa beraktifitas membobol kendaraan roda dua yang memiliki nilai jual tinggi. Melalu penelitian ini, maka penulis memberikan sebuah alternative bagi sistem keamanan motor pada sisi sistem kontak dan starter motor. Dengan memanfaatkan alat/komponen tambahan yaitu smartphone, bluetooth, mikrokontroller, maka penulis berhasil membuat sebuah sistem starter pada sepeda motor dengan baik tanpa mengurangi/mempengaruhi kinerja dari kendaraan tersebut. Sistem kontak (stand by) pada motor hanya bisa diaktifkan menggunakan smartphone melalui bluetooth, untuk menghidupkan mesin secara elektrik (dynamo starter) juga hanya bisa dilakukan oleh smartphone, akan tetapi sistem starter manual (engkol) juga tetap bisa digunakan ketika kontak dalam keadaan "stand by".
\end{abstract}

Kata kunci: Smartphone, Bluetooth, mikrokontroller, starter sepeda motor

\section{PENDAHULUAN}

Seiring dengan perkembangan jaman, maka kebutuhan manusia akan alat transportasi semakin meningkat, salah satunyasepeda motor. Selain karena harganya yang relative terjangkau, bahan bakar yang irit, sepeda motor juga dianggap sebagai alat transportasi yang paling efektif dan efisien digunakan, terutama untuk jalan yang padat sehingga sedikit banyak bisa terhindar dari kemacetan. Hal inilah yang mendorong tingginya penggunaan sepeda motor di Indonesia. Berdasarkan data dari BPS bahwa pada tahun 2016, jumlah sepeda motor di Indonesia mencapai 105,15 juta unit atau lebih dari $81 \%$ jumlah kendaraan bermotor nasional. Seiring berkembangnya jumlah sepeda motor, tingkat pencurian sepeda motor juga semakin marak, terutama kepada sepeda motor yang memiliki nilai/harga jual tinggi.

Berbagai cara telah dilakukan oleh pemilik kendaraan sepeda motor, mengganti kunci standar pabrikan dengan menggunakan kunci khusus, menambah gembok pada cakram, maupun pengunci jari-jari dan sebagaiya. Cara-cara tersebut tetap saja masih bisa "dibobol" oleh pencuri. Oleh karena itu melalui penelitian ini, penulis ingin menawarkan sebuah alternative baru bagi sistem keamanan motor khususnya pada sistem kontak da starter motor menggunakan handphone.

Berbagai type handphone saat ini, salah satunya smartphone, menyediakan fitur-fitur yang bisa dimanfaatkan sebagai pengendali, apalagi didukung sistem operasi yang open source, memberikan kemudahan bagi kita untuk melakukan berbagai riset pengembangan sesuai dengan keinginan/kebutuhan. Salah satu fitur pada smarthphone yaitu Bluetooth dapat dimanfaatkan sebagai pengendali kepada bagi sistem kontak dan starter pada sepeda motor yang diproses oleh mikrokontroller.

Mikrokontroller merupakan salah satu pengendali berukuran mikro, yang dapat digunakan bersamaan dengan alat elektronika lainnya untuk aplikasi suatu sistem kendali. Pemakaian mikrokontroller umumnya digunakan dalam embedded system.Dengan kombinasi antara smarthpone, bluetooth dan mikrokontroller ini diharapkan akan menghasilkan sebuah sistem kontak dan pengendali starter menggantikan sistem dari pabrikan, dengan tujuan utama untuk sistem keamanan dari sepeda motor yaitu meminimalisir pencurian terhadap sepeda motor. 


\section{METODE PENELITIAN}

Metode yang digunakan untuk merancang dan membangun sistem ini adalah dengan melakukan pendekatan secara model waterfall dimana sebuah pendekatan terhadap pengembangan perangkat lunak yang sistematik, dengan beberapa tahapan, yaitu: analysis, design, coding, testing dan maintenance.

\section{A. Analisis Kebutuhan Sistem}

Langkah pertama dalam penelitian ini adalah, penulis melakukan observasi terhadap sistem kelistrikan dari sepeda motor, khususnya pada sistem instalasi kontak motor dan starter baik itu manual maupun elektrik. Tujuanya agar dapat dilakukan modifikasi sehingga sistem tersebut dapat dikendalikan oleh smarthphne melalui bluetooth dan diproses oleh mikrokontroller.

Dari hasil observasi tersebut, penulis dapat menarik kesimpulan awal akan kebutuhan sistem yang diperlukan dan juga perangkat keras maupun lunak. Untuk kebutuhan inputsistem dibutuhkan sebuah smarthphone yang berbasis android OS dan memiliki bluetooth dan tombol on/off. Sedangkan perangkat keras lainnya utuk pengendali terdiri dari arduinouno, modul bluetooth dan relay $12 \mathrm{~V}$. Sedangkan perangkat lunak dibutuhkan pemograman java dengan menggunakan IDEEclipse serta pemograman $\mathrm{C}$ dengan menggunakan IdeArduino.

\section{B. Perancangan Sistem}

1. Arsitektur Sistem

Arsitektur sistem yang dibangun untuk mendukung penelitian rancang bangun sistem starter sepeda motor menggunakan smartphone berbasis mikrokontroller yang dibuat adalah sebagai berikut :

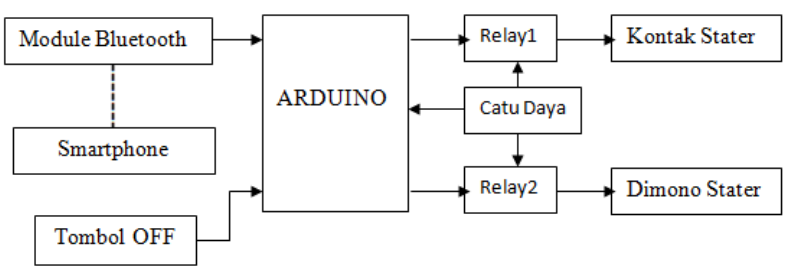

Gambar 1. Arsitektur Sistem

- Pada Gambar 1, terlihat bahwa rancang bangun startersepeda motor menggunakan smartphone terdiri dari beberapa komponen, yaitu : smartphone sebagai pengontrol yang memberikan perintah untuk diproses oleh Arduino.

- Module bluetooth sebagai penerima data agar dapat diproses oleh arduino.

- Relay sebagai perangkat keluaran yang terhubung dengan kontak starter dan dinamostarter, fungsinya untuk menghidupkan dan mematikan kontak starter dan dinamostarter.

- Catu daya fungsinya memberikan daya ke arduino dan relay.

- Tombol fungsinya untuk mematikan relay1 (kontak starter) secara manual.

\section{Use Case dan activity Diagram Sistem}

Deskripsi kerja sistem dapat dijabarkan menggunaka use case diagram seperti dibawah ini.



Gambar 2.Use Case Diagram Sistem



Gambar 3.Activity Diagram Sistem

Penjelasan activity diagram:

- Login, pada tahap ini user harus memasukan password pada aplikasi untuk bisa menggunakan aplikasi.

Inisialisasi koneksi smartphone dan arduino, pada tahap ini user memulai aplikasi dan melakukan koneksi dari bluetoothsmartphone ke module bluetooth pada mikrokontroller. 
- Perintah ON atau OFF dari smartphone, tahap ini mengirimkan perintah dari interface di smartphone agar dapat diproses oleh mikrokontroller.

- Menghidupkan/mematikan motor dari smartphone, pada tahap ini sudah bisa menghidupkan atau mematikan mesin sepeda motor menggunakan smartphone.

- Menghidupkanmotor menggunakan starterengkol, pada tahap ini mesin sepeda motor juga bisa dihidupkan dengan starterengkol atau secara manual.

3. Desain Interface aplikasi

Pada smartphoneakan dibuat sistem interface antara user dengan perangkat smartphone, untuk mengendalikan sistem.

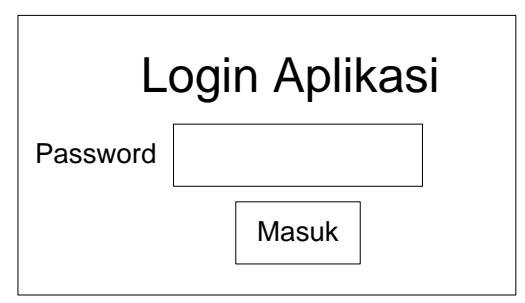

Gambar 4.Tampilan Login



Gambar 5.Tampilan Main Menu

C. Pengkodean

Pada tahap pengkodean sistem, penulis menuliskan codding untuk membangun sistem terdiri dari 2 bahasa pemrograman :

- Pemograman java, menggunakan IDEEclipse

- Pemograman C, menggunakan IdeArduino.

- Menggunakan tools simulator (proteus) untuk melakukan pengujian hardware (arduino dan relay).

\section{Pengujian Sistem}

Pada tahap ini, penulis melakukan pengujian untuk megetahui tingkat kebenaran dan akurasi sistem. Proses-proses pengujian dilakukan pada interfacehandphone, koneksi bluetooth, pemrosesan arduino dan kinerja relay.

\section{HASIL DAN PEMBAHASAN}

\section{HASIL}

A. Aplikasi Android

Jalankan aplikasi yang telah dibuat pada smarthphone, dan menginput password dan kemudian "masuk".

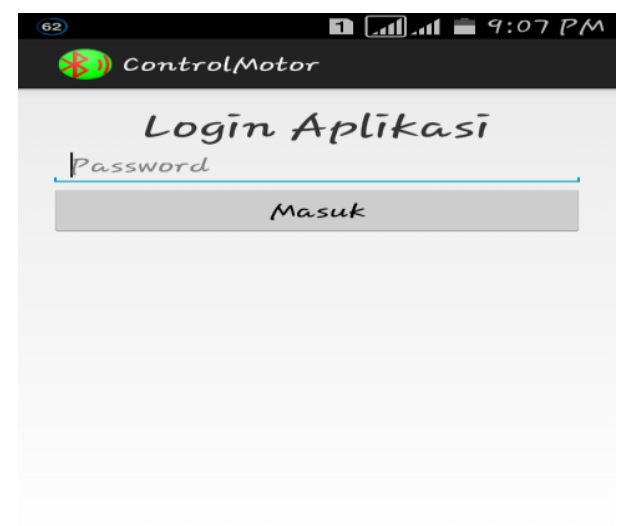

Gambar 6. Login Aplikasi

Setelah userberhasil login, akan muncul tampilan menu utama seperti gambar dibawah.



\section{Gambar 7.Tampilan Menu Utama}

Sebelum mengoperasikan aplikasi untuk dieksekusi oleh mikrokontroller, maka user harus melakukan koneksi ke modul bluetooth pada arduino, dengan tekan tombol "connect $B T$ ". Setelah itu akan tampil daftar perangkat bluetooth yang terdeteksi dan aktif, kemudian user memilih $\mathrm{HC}-05$. 


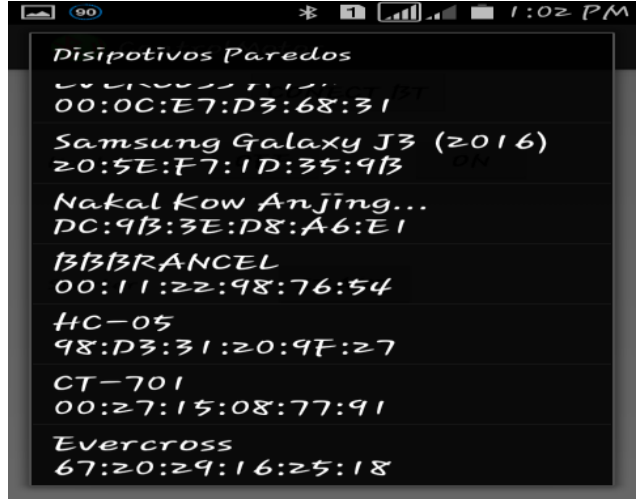

Gambar 8. Perangkat Terhubung

Jika sudah terhubung maka tombol ConectBTakanberubahseperti pada gambar 9. Ini menandakan bahwa smartphone telah terkoneksi dengan modul bluetooth pada arduino. Sampai pada titik ini, user sudah bisa mengoperasikan perintahperintah lainnya.

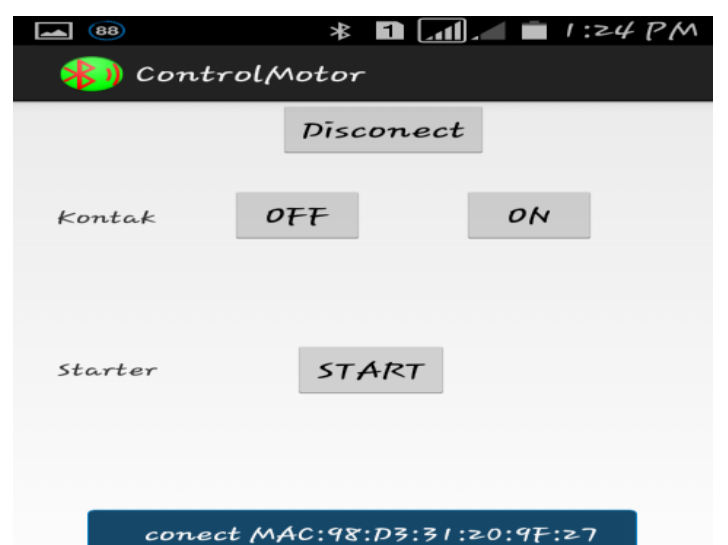

Gambar 9.Koneksi Antar Bluetooth

Setelah terkoneksi, maka user menekan tombol ON untuk menghidupkan kontak. Pada kondisi ini, mesin sepeda motor siap untuk dihidupkan. Mesin dapat dihidupkan secara elektrik dengan mendapat perintah dari smartphone (tekan start), atau dapat pula dihidupkan secara manual (engkol). Sedangkan tombol OFF untuk mematikan kontak sekaligus mesin sepeda motor.

\section{B. RangkaianHardware}

Gambar 10 merupakan gambar rangkaian hubungan antar perangkat keras dengan sistem kelistrikan motor khususya untuk sistem starter.

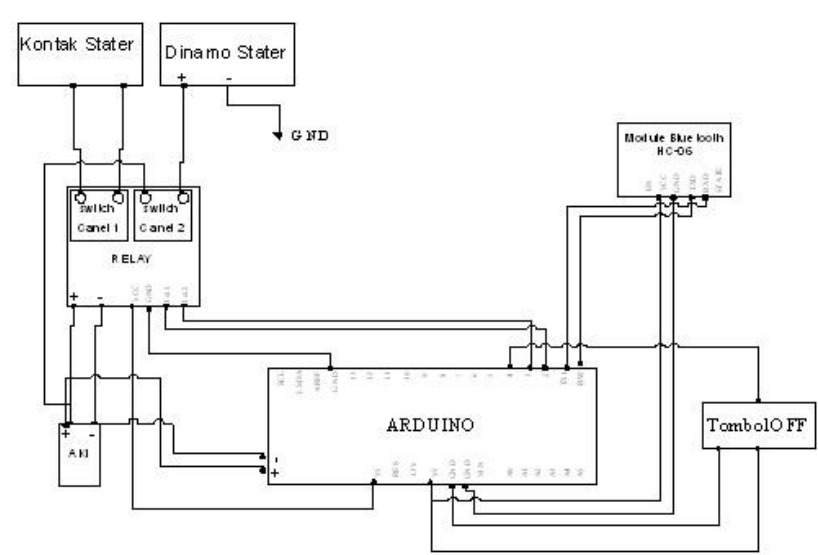

Gambar 10.RangkaianHardware

Keterangan :

1. Module Bluetooth dan Arduino

- Pin VCCbluetooth terhubung ke 5V pada arduino

- Pin GND bluetooth terhubung ke GND pada arduino

- Pin TX bluetooth terhubung ke Pin RX pada arduino

- Pin RXbluetooth terhubung ke Pin TX pada arduino

2. Relay dan Arduino

- Pin VCC relay terhubung ke Pin 5V pada arduino

- Pin GND relay terhubung ke Pin GND pada arduino

- Pin int1 relay terhubung ke Pin 2 pada arduino

- Pin int2 relay terhubung ke Pin 3 pada arduino

3. Tombol dan Arduino

- Pin + pada tombol terhubung ke Pin 5V dan Pin 4 pada arduino

- Pin - pada tombol terhubung ke Pin GND pada arduino

4. Relay dan Kontak Starter

Switch pada relay terhubung ke arus kiprok dan coil pada sepeda motor

5. Relay dan Dinamo Starter

Switch pada relay terhubung ke dinamostarter

6. AKI

Aki memberikan daya $12 \mathrm{~V}$ ke arduino, $12 \mathrm{~V}$ ke relay dan $12 \mathrm{~V}$ ke dinamostarter.

C. Pengujian Sistem

Pengujian sistem telah dilakukan dan memberikan hasil sesuai dengan yang diharpkan. Pegujian dilakukan degan beberapa metode, yaitu:

1. Pengujian Instruksi dari smartphone kepada sepeda motor. 
Tabel 1. Pengujian Aplikasi pada smartphone dan sepeda motor.

\begin{tabular}{|c|c|c|c|}
\hline No & $\begin{array}{c}\text { Jenis } \\
\text { Pengujian }\end{array}$ & Harapan & Hasil \\
\hline 1 & $\begin{array}{l}\text { Klik icon pada } \\
\text { menu }\end{array}$ & $\begin{array}{l}\text { Aplikasi } \\
\text { running }\end{array}$ & Sesuai \\
\hline 2 & $\begin{array}{l}\text { Memasukkan } \\
\text { password yang } \\
\text { benar }\end{array}$ & $\begin{array}{l}\text { Masuk ke } \\
\text { menu } \\
\text { utama }\end{array}$ & Sesuai \\
\hline 3 & $\begin{array}{l}\text { Memasukkanp } \\
\text { assword yang } \\
\text { salah }\end{array}$ & $\begin{array}{l}\text { Tetap di } \\
\text { menu login }\end{array}$ & Sesuai \\
\hline 4 & $\begin{array}{l}\text { Menekan } \\
\text { tombol } \\
\text { conectBT }\end{array}$ & $\begin{array}{l}\text { Tampil } \\
\text { daftar } \\
\text { perangkat } \\
\text { bluetooth } \\
\text { aktif }\end{array}$ & Sesuai \\
\hline 5 & $\begin{array}{l}\text { Memilih } \\
\text { bluetooth HC- } \\
05\end{array}$ & $\begin{array}{l}\text { Terkoneksi } \\
\text { dengan } \\
\text { module } \\
\text { bluetooth }\end{array}$ & Sesuai \\
\hline 6 & $\begin{array}{l}\text { Menekan } \\
\text { tombol ON }\end{array}$ & $\begin{array}{l}\text { Kontak } \\
\text { hidup }\end{array}$ & Sesuai \\
\hline 7 & $\begin{array}{l}\text { Menekan } \\
\text { tombol start }\end{array}$ & Motor hidup & Sesuai \\
\hline 8 & $\begin{array}{l}\text { Startersecara } \\
\text { manua }\end{array}$ & motor hidup & Sesuai \\
\hline 9 & $\begin{array}{l}\text { Menekan } \\
\text { tombol OFF }\end{array}$ & Motor mati & Sesuai \\
\hline 10 & $\begin{array}{l}\text { Menekan } \\
\text { tombol secara } \\
\text { manual }\end{array}$ & Motor mati & Sesuai \\
\hline
\end{tabular}

2. Pengujian Kompatibilitas

Pengujian dilakukan pada beberapa smartphone android dengan versi yang berbeda dengan cara menginstal file $A P K$ kedalam smartphone dan selanjutnya mencoba semua fungsi tombol pada interface.

Tabel 2. Tabel Pengujian Kompitibilitas Aplikasi Pada Smartphone.

\begin{tabular}{|c|c|c|c|c|c|c|}
\hline \multirow[b]{2}{*}{ No } & \multirow[b]{2}{*}{$\begin{array}{c}\text { Nama } \\
\text { Perangkat }\end{array}$} & \multirow[b]{2}{*}{ Versi } & \multicolumn{4}{|c|}{ Jenis Pengujian } \\
\hline & & & $\begin{array}{l}\text { Pemasangan } \\
\text { Aplikasi }\end{array}$ & $\begin{array}{l}\text { Tampilkan } \\
\text { Aplikasi }\end{array}$ & $\begin{array}{l}\text { Tampilkan } \\
\text { Daftar } \\
\text { Bluetooth }\end{array}$ & $\begin{array}{c}\text { Tampilkan } \\
\text { Fungsi } \\
\text { Tombol }\end{array}$ \\
\hline 1 & $\begin{array}{l}\text { Samsung } \\
\text { J1 Ace }\end{array}$ & $\begin{array}{l}\text { Sistem } \\
\text { Operasi } \\
\text { Android } \\
\text { V5.1.1 } \\
\text { Lolipop }\end{array}$ & Berhasil & Berhasil & Berhasil & Berhasil \\
\hline 2 & $\begin{array}{l}\text { Citicall CT- } \\
701\end{array}$ & $\begin{array}{l}\text { Sistem } \\
\text { Operasi } \\
\text { Android v4.4 } \\
\text { Kitkat }\end{array}$ & Berhasil & Berhasil & Berhasil & Berhasil \\
\hline 3 & $\begin{array}{l}\text { Oppo Neo } \\
5\end{array}$ & $\begin{array}{l}\text { Sistem } \\
\text { Operasi } \\
\text { Android v6.0 } \\
\text { Marshmallow }\end{array}$ & Berhasil & Berhasil & Berhasil & Berhasil \\
\hline
\end{tabular}

3. Pengujian kemampuan Bluetooth mengirim sinyal

Pengujian ini dilakukan dengan tujuan mengetahui sejauh mana Bluetooth pada smartphone mengirim sinyal dan ditangkap oleh modul bluetoothpada sistem yang terpasang pada sepeda motor.

Tabel 3. Tabel Pengujian Kehandalan Koneksi Sesama Bluetooth

\begin{tabular}{ccl}
\hline No & $\begin{array}{c}\text { Jarak } \\
\text { (Meter) }\end{array}$ & \multicolumn{1}{c}{ Hasil } \\
\hline 1 & 1 & Baik \\
2 & 5 & Baik \\
3 & 10 & Baik \\
4 & 15 & Baik \\
5 & 20 & Baik \\
6 & 23 & Baik \\
7 & 24 & Kurang baik \\
8 & 25 & Buruk \\
9 & 26 & Tidak ada koneksi \\
\hline
\end{tabular}

\section{PEMBAHASAN}

Pembuatan aplikasi system dibuat dalam beberapa tahap yaitu :

1. Pemograman Pada Arduino IDE

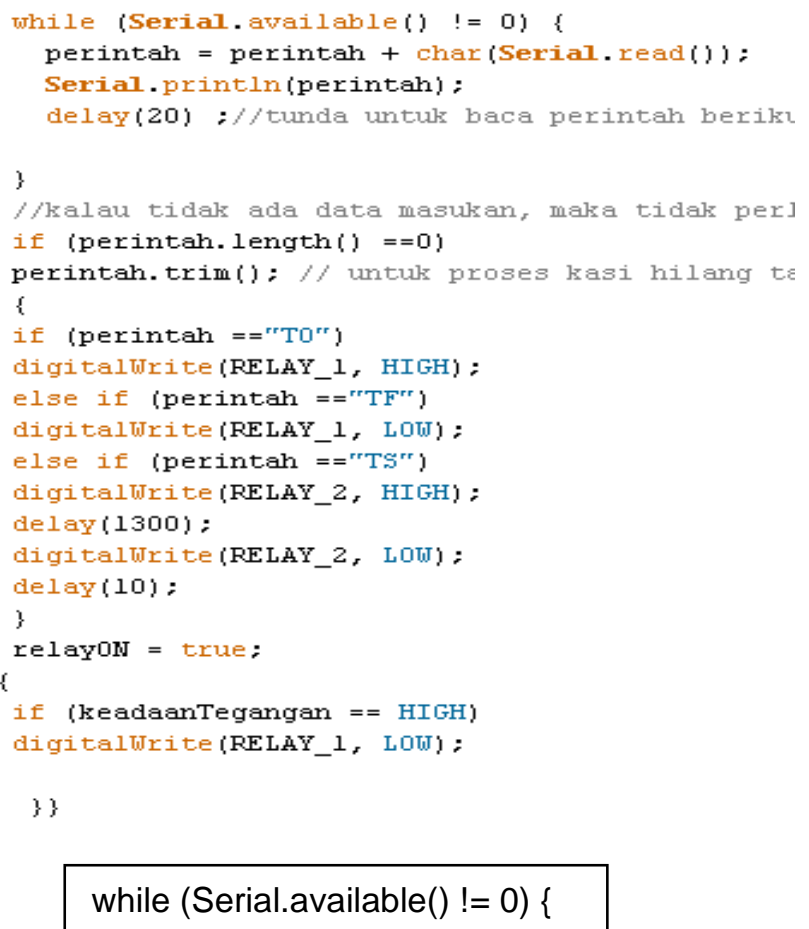

Fungsi dari perintah di atas adalah untuk membaca perintah dari serial jika perintah kosong maka arduino tidak memproses apa-apa.

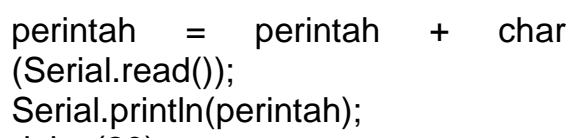


maka program akan menampilkan informasi "Bluetoothh Device Not Available", dan jikaa bluetooth device terpasang paka program akan mengaktifkan bluetooth pada Perangkat.

e. Pemograman untuk kirim karakter ke arduino

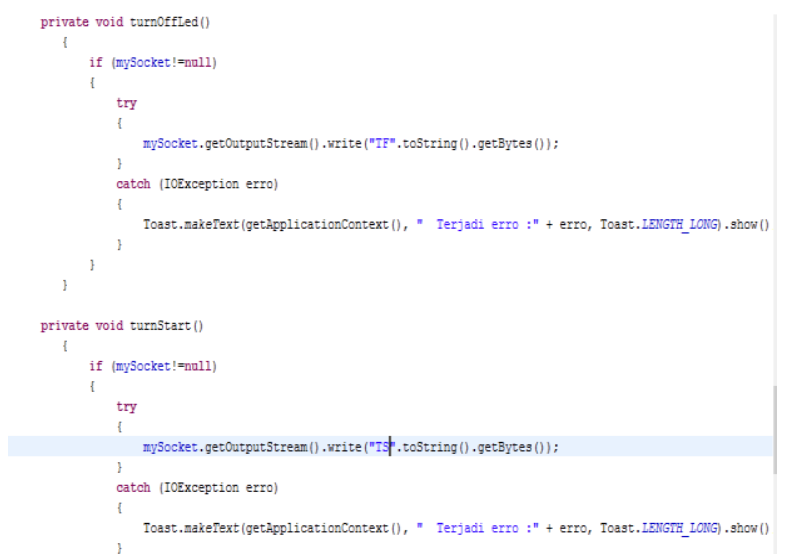

Penjelasan dari perintah di atas untuk mengirim karakter berupa TO, TF, dan TS ke Arduino melalui OutputStream kebluetoothsocket.

\section{PENUTUP}

\section{A. Kesimpulan}

Berdasarkan hasil pegujian terhadap sistem yang telah dibuat, maka penulis dapat menarik beberapa kesimpulan :

1. Pembuatan sistem starter menggunakan smartphone dan mikrokontroller berhasil dibuat dengan media komunikasi bluetooth.

2. Pembuatan aplikasi interfaceandroid sebagai pengontrol dari smartphone berhasil dibuat dan dapat berjalan dengan baik pada android OS versi 4.4 keatas.

3. Pengujian koneksi antara Bluetooth pada smartphone dengan modul bluetooth yang terhubung pada arduino dapat berjalan dengan baik dan jarak maksimal koneksi adalah 23 meter.

4. Sistem kontak motor dapat dikendalikan secara penuh menggunakan smartphone, dan motor dapat distarter maupun dimatikan menggunakan aplikasi android.

5. Sistem starter secara manual (engkol) tetap dapat berfungsi dengan baik, setelah sistem kontak dihidupkan oleh smartphone.

\section{B. Saran}

Tujuan utama dari membangun sistem ini adalah member keamanan bagi pegguna motor agar dapat meminimalisir terhadap pecuria kendaraan bermotor, oleh karea itu penulis merasa belumlah tentu sistem yang kami buat ini dapat menjawab secara penuh terhadap kebutuhan user, oleh karena itu penulis memiliki bebebrapa saran terkait pengembangan sistem ini, yaitu :

1. Sistem dapat ditambahkan sistem GPS Tracker, sehingga dapat dikontrol pergerakan sepeda motor berdasarkan titik koordinat.

2. Sistem yang dibangun ini meggunakan arduino uno, tetapi dapat juga menggunakan arduino nano karena secara fisik lebih kecil dan harganya lebih murah.

\section{UCAPAN TERIMAKASIH}

Penelitian rancang bangun sistem starter pada sepeda motor berbasis smartphone dan mikrokontroller ini tidak akan selesai tanpa bantuan dari reka-rekan peneliti, oleh karena itu penulis mengucapkan terima kasih kepada rekan-rekan peneliti, karena kita kita telah dapat bekerja sama dengan baik dan mampu menhasilkan prototype ini. Kiranya kebersamaan kita dalam penelitian ini tetap dapat dipertahankan untuk penelitian selanjutnya maupun pengembangan prototype yang dihasilkan saat ini.

\section{DAFTAR PUSTAKA}

Andrianto H. 2008. Pemrograman Mikrokontroler AVR ATMega8 menggunakanbahasa $C$. Bandung: Informatika.

Artanto D. 2012. Interaksi Arduino dan LabVIEW. Jakarta: Elex Media Komputindo.

Harinoto, Fendi. 2007. Sistem Pengaman Sepeda Motor Via RFID dan sms menggunakan mikrokontroller atmega 128. Jember : Universitas Muhammadiyah.

Nazarudin S. 2010. Pemrograman Aplikasi Mobile Smartphone dan Tablet PC Berbasis Android. Bandung: Informatika.

Putu, Giovanni. 2012. Mengenal Relay. Jakarta : Penerbit Informatika.

Dillak, R. (2017). KLASIFIKASI MUSIK MENGGUNAKAN POLYNOMIAL NEURAL NETWORK. Jurnal IImiah Flash, 3(2), 94-99

Safaat H, \& Nazruddin.2012. Pemrograman Aplikasi Mobile Smartphone dan Tablet PC berbasis Android. Bandung: Penerbit Informatika.

Tjhin, Santo, 2014,Sistem Keamanan Sepeda Motor Melalui Short Message Service

Menggunakan AVR Mikrokontroler atmega8. Skripsi Terpublikasi, Yokyakarta: STMIK Raharja.

Winoto A. 2010. "Mikrokontroler AVR ATmega8/16/32/8535 dan Pemrograman dengan Bahasa $C$ pada WinAVR, Bandung: Penerbit Informatika Bandung. 